\title{
I Consenso Nacional para Padronização dos Laudos de FAN HEp-2
}

\section{The first Brazilian Consensus for Standardization of ANA in HEp-2 Cells}

unitermos
FAN
Imunofluorescência
Doenças auto-imunes

resumo

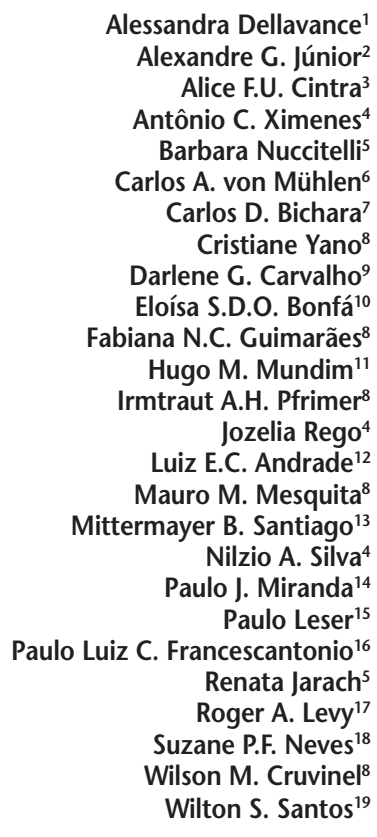

A análise da presença de auto-anticorpos feita por imunofluorescência indireta em células

HEp-2 constitui-se em um método de triagem escolhido na maioria dos laboratórios clínicos.

A ausência de uma nomenclatura definida para a descrição dos laudos tem trazido problemas

na utilização clínica do teste, pelas dificuldades no controle de qualidade e na padronização

dos resultados, que, por sua vez, embora similares, recebiam denominações diferentes.

O I Consenso Brasileiro para Padronização dos Laudos de FAN HEp-2 reuniu em agosto de

2000, em Goiânia, diversos especialistas de todo o Brasil. Esses emitiram pareceres em

consenso para os distintos padrões: nucleares, nucleolares, citoplasmáticos e aparelho

mitótico. Foram feitas recomendações sobre os critérios para a leitura de uma lâmina, bem

como para relação entre a diluição de triagem e o sistema óptico utilizado.

\section{abstract}

The technique of immunofluorescence using HEp-2 cells as substrate is the screening method of choice for the presence of autoantibodies in many clinical laboratories. The lack of a specific terminology for reporting results brings problems in quality control, clinical utility of the test, and standardization attempts. The first Brazilian Consensus for Standardization of ANA in HEp-2 Cells took place in Goiânia in August 2000. Several laboratory specialists with experience in the methodology showed up. They established guidelines for the description of ANA patterns in the Portuguese language, encompassing distinct descriptions for nuclear, nucleolar, cytoplasmic and mitotic apparatus patterns of fluorescence. Recommendations were also established regarding screening titers, final dilution titer, and on morphological criteria for reading the slides.

\section{key words}

\section{ANA}

Immunofluorescence

Autoimmune diseases
Laboratório Fleury e USP. SP.

2. Centro Imuno Reumatológico

de São Paulo, SP

3. Biorad Diagnósticos, R.

4. Universidade Federal de Coiás, CO.

5. Laboratório Clínico Padrão, CO

6. Pontifícia Universidade Católica, RS.

7. Laboratório Amaral Costa, PA.

8. Universidade Católica de Coiás, CO

9. Laboratório Pardini, MC.

10. USP, SP.

11. Laboratório Exame, DF

12. EPM/Unifesp, SP.

13. EBMSP, BA.

14. Universidade Federal de

Pernambuco, PE

15. Laboratório Fleury, SP.

16. Laboratório Padrão e UCG, CO.

17. UER/ e Laboratório Labs, R.

18. UFMG, MG.

19. Hospital de Base, DF. 


\section{Introducão}

As primeiras descrições sobre auto-anticorpos ocorreram em doenças reumáticas auto-imunes, como o fator reumatóide na artrite reumatóide e o fenômeno LE no lúpus eritematoso sistêmico (LES). A célula LE foi descrita por Hargraves em 1948, tendo sido utilizada por muitos anos como marcador sorológico para o diagnóstico de LES (4). Sendo uma técnica trabalhosa, demorada e de difícil interpretação, foi substituída nas últimas décadas por outros métodos para a pesquisa e identificação de autoanticorpos. A técnica de imunofluorescência indireta foi adaptada para a pesquisa de auto-anticorpos em 1957, por Fries. Desde então diversos substratos antigênicos foram utilizados, como, por exemplo, corte de fígado ou rim de rato, imprint de fígado de camundongo, leucócitos humanos e diversas linhagens celulares. Estes substratos foram substituídos largamente por células HEp-2 (1). Estas células imortalizadas originam-se de carcinoma laríngeo humano e crescem em monocamadas sobre lâminas de vidro. As vantagens do uso de células HEp-2 são:

- Primeira: possuem antígenos humanos não-encontrados em tecidos de roedores, e os antígenos semelhantes estão em maior concentração.

- Segunda: apresentam todas as fases de divisão celular, interfase/prófase, metáfase, anáfase e telófase, cada uma delas sendo a expressão fenotípica da atuação de uma série de genes, que codificam uma miríade de proteínas que surgem, reagem, atuam e desaparecem, de acordo com as fases do ciclo de vida celular, e que funcionam como auto-antígenos que possibilitam a identificação de inúmeros auto-anticorpos.

- Terceira: possuem uma relação núcleo/citoplasma em favor do núcleo, característica neoplásica, que facilita o reconhecimento de vários rearranjos fluorescentes.

- Quarta: possuem vários nucléolos, permitindo avaliar sua forma de apresentação nos padrões nucleolares.

- Por último, têm um citoplasma rico em fibrilas e organelas, fundamentais no reconhecimento dos padrões citoplasmáticos.

Se em 1957 eram reconhecidos apenas quatro padrões de FAN, atualmente as células HEp-2 permitem o reconhecimento de mais de 30 diferentes padrões nucleares, nucleolares, da membrana nuclear, do aparelho mitótico e citoplasmáticos, que são dados por diferentes autoanticorpos. A vantagem do método é a sua grande sensibilidade, que permite a triagem de uma gama imensa de anticorpos, fornece uma idéia da concentração dos mes- mos e uma informação qualitativa importante que pode ser usada como um passo inicial para uma identificação específica (5).

A identificação de anticorpos antinucleares exerce um papel importante na clínica médica e na imunologia clínica (6). A detecção de anticorpos antinucleares para diagnóstico de doenças sistêmicas, intermediárias ou órgãoespecíficas tem aumentado progressivamente desde que a técnica de imunofluorescência foi utilizada como triagem de auto-anticorpos.

Alguns padrões de fluorescência são relativamente inespecíficos, podendo ser evocados por vários autoanticorpos distintos (pontilhado grosso associado a antígenos Sm e U1RNP). Outros padrões de fluorescência, entretanto, são ocasionados por uma gama restrita de auto-anticorpos (PCNA), e outros, ainda, exclusivamente por um único auto-anticorpo (centromérico). Nestas circunstâncias, o padrão de fluorescência per se pode ser suficiente para a definição da especificidade do autoanticorpo. Na maior parte das vezes, entretanto, o padrão de fluorescência não pode identificar qual o autoanticorpo presente, mas sua definição é de vital importância, pois pode sugerir ao clínico ou patologista clínico qual o próximo passo na investigação de sua especificidade. Os ensaios para identificação dos autoanticorpos (imunodifusão dupla, contra-imunoeletroforese, hemaglutinação passiva, Elisa, imunoprecipitação, imunodot e Western-blot) são específicos para cada teste. Assim, o FAN-HEp-2 apresenta-se como importante método de triagem, pois possibilita o conhecimento do(s) anticorpo(s) provavelmente envolvido(s), restringindo assim os pedidos laboratoriais e colaborando com a viabilidade econômica do processo.

Apesar de o FAN testado em células HEp-2 ser um método sensível, com capacidade de rastrear uma grande variedade de auto-anticorpos conhecidos e desconhecidos e oferecer indicações sobre a provável identidade do antígeno, apresenta como limitação variações na interpretação dos padrões de imunofluorescência. A nomenclatura utilizada para definição dos padrões de fluorescência em nosso país foi forjada informalmente, muitas vezes sendo adaptada a partir de nomenclatura estrangeira, seja do idioma inglês, francês ou espanhol. O resultado inevitável desse processo foi o aparecimento de uma variedade de nomes de padrões, muitos dos quais destinados a descrever o mesmo aspecto morfológico. Assim, por exemplo, temos os termos "salpicado", "pontilhado", "moteado", "granular" e "filamentoso", que têm sido usados por 
diferentes observadores para designar o que se vê na literatura anglo-saxônica como speckled, dificultando sobremaneira a interpretação do resultado para o clínico.

\section{Metodologia}

A idéia de organizar um consenso sobre laudos de FANHEp-2 surgiu em 1993 durante uma apresentação do professor Paulo Leser no Congresso Anual de Patologia Clínica. A execução dessa proposta, porém, só foi possível com a criação do Laboratório de Auto-Imunidade do Departamento de Ciências Biomédicas da Universidade Católica de Goiás e a aquisição de um microscópio de fluorescência com câmara digital, mediante projeto de pesquisa financiado pela Secretaria de Ciência e Tecnologia do Estado de Goiás e pela Universidade Católica de Goiás.

Foi adquirido um microscópio DMLB, marca Leica, trinocular, com revólver sêxtuplo e com objetivas $\mathrm{N}$ planacromáticas de correção infinita, além destas propriedades: condensador universal NA1.30 para contraste de fase, campo escuro e campo claro, iluminação transmitida para campo claro de 100 watts, acoplada com sistema de fluorescência, lâmpada de vapor de mercúrio de alta pressão, 100 watts e filtros FIPC para acridine orange e RG N2.1 para ficoeritrina e BG 38 para isotiocianato de fluorceína. Ao microscópio foi acoplada microcâmara digital DC200, marca Leica, para pesquisa e análise de imagens com resolução de 2,64 megapixel, CCD 2/3 de polegada e integração de 18 imagens por segundo.

A composição do grupo participante foi baseada em três critérios: a) indicações feitas pela Sociedade Brasileira de Reumatologia, pela Sociedade Brasileira de Patologia Clínica, pela Sociedade Brasileira de Análises Clínicas e pelo Conselho Federal de Biomedicina; b) reconhecida experiência acadêmica e profissional; c) capacidade de multiplicação dos resultados com a participação de especialistas de diversos centros nacionais, como Goiânia, Brasília, Belo Horizonte, Salvador, Recife, São Paulo, Rio de Janeiro, Porto Alegre e Belém.

Sintonizado com esse problema, um grupo de estudiosos de auto-anticorpos afeitos à leitura de testes de imunofluorescência indireta reuniu-se nos dias 18 e 19 do mês de agosto de 2000, em Goiânia. O I Consenso Nacional para Padronização dos Laudos de FAN HEp-2 foi organizado pela Universidade Católica de Goiás, tendo recebido vários patrocínios.

O Laboratório de Auto-Imunidade (LAI/CBB/UCG), em conjunto com a Escola de Computação da UCG, produziu previamente um $\mathrm{CD}$ em que constava uma árvore de decisão proposta pelo grupo de Goiânia, juntamente com imagens digitalizadas de FAN-HEp-2. O clique na célula do organograma da árvore permitia a visualização do grupo de imagens correspondentes, utilizando-se a estratégia de captura de vários campos, como se o observador estivesse correndo a lâmina no microscópio. Em cada campo visualizado havia sempre células em um dos estágios da divisão celular. O programa permitia a abertura de uma janela que possibilitava a emissão do laudo pelo observador, que poderia ser salvo em disquete e remetido ou transmitido por e-mail ao LAl. Foi feita uma estatística dos padrões emitidos pelos diferentes profissionais, a qual foi utilizada nas discussões da plenária dos dias 18 e 19 de agosto.

Durante dois dias foram analisadas dezenas de imagens digitalizadas de FAN, sobre as quais houve acirrado debate, discutindo-se a nomenclatura e possíveis significados práticos. Ao final, chegou-se a uma nomenclatura uniforme para os principais padrões de fluorescência nuclear, nucleolar, aparelho mitótico e citoplasmático. Conscientes de que a diversidade de aparelhos de microscopia e a heterogeneidade no grau de experiência com leitura de imunofluorescência indireta acarretam grande variação na capacidade de reconhecer os padrões de fluorescência, os participantes do consenso definiram os critérios de leitura de uma lâmina, as diluições empregadas e os padrões mínimos a serem identificados e relatados.

A seguir apresentamos as recomendações do I Consenso Nacional para Padronização dos Laudos de FAN HEp-2, que devem ser seguidas juntamente com as árvores de decisão (Figura 1). Os critérios a ser seguidos são:

- as diluições de triagem são 1/40 e 1/160, na dependência da lâmpada do microscópio (20W, 50W, 100W);

- os critérios morfológicos a ser observados durante a leitura da lâmina:

a) aspecto da matriz nuclear;

b) aspecto do nucléolo;

c) observação de todos os estágios de divisão celular;

d) aspecto do fuso mitótico;

e) aspecto do citoplasma.

- A combinação desses critérios resultou nas seguintes árvores de decisões:

1. padrões nucleares;

2. padrões nucleolares;

3. padrões relacionados ao aparelho mitótico;

4. padrões citoplasmáticos. 


\section{Padrões nucleares}

Os padrões nucleares foram divididos em três grandes categorias: membrana nuclear, homogêneo e pontilhado.

\section{Padrão tipo membrana nuclear}

Esta denominação foi adotada para diferenciá-la do antigo padrão periférico utilizado quando do uso de imprint de fígado de rato, onde o DNA de dupla hélice se encontrava ancorado às proteínas da membrana nuclear, dando seu aspecto característico e que não encontra o mesmo significado quando do uso de células HEp-2. O período em que ocorre o ancoramento nestas células é muito curto e praticamente não encontrado na rotina laboratorial. O padrão é composto por uma fluorescência em toda a membrana nuclear (podendo ser emitida com informação adicional, em aspecto contínuo ou pontilhado). Não observamos fluorescência em nucléolos; a célula em divisão, em todos os estágios, e o citoplasma apresentam-se não-fluorescentes (Figura 2).

\section{Padrão homogêneo}

Apresenta o nucleoplasma fluorescente. Não é possível distinguir a área de nucléolo. A célula em divisão, em todos os estágios, é fluorescente, com decoração homogênea dos cromossomos. Citoplasma normalmente nãofluorescente (Figura 3).

\section{Padrão pontilhado}

A dificuldade de diferenciação dos tamanhos e formas com que os grânulos se apresentam fez com que o consenso considerasse obrigatório o laudo de padrão pontiIhado. O grupo dos pontilhados foi dividido em mitose fluorescente e não-fluorescente. No subgrupo da mitose não-fluorescente foram considerados obrigatórios os laudos que se seguem.

\section{Pontilhado pleomórfico}

O nucleoplasma apresenta-se totalmente não-fluorescente na célula em fase G1 da interfase, passando a pontilhado com grânulos, variando de grosso, fino a fino denso na medida em que a célula evolui para as fases $S$ e G2. Nucléolo, célula a partir da metáfase e citoplasma nãofluorescentes. Típico de PCNA (Figura 4).

\section{Pontilhado do tipo pontos isolados}

Nucleoplasma apresenta-se com pontos fluorescentes isolados (podendo ser fornecido, como informação adicio- nal, o número de pontos maior ou igual a dez ou menor do que dez pontos por núcleo). Nucléolo, célula em divisão e citoplasma não-fluorescentes (Figura 5).

A informação adicional a respeito do padrão pontilhado pode ser fornecida na dependência do equipamento ótico utilizado, bem como da experiência do observador nos diagnósticos a seguir.

\section{Pontilhado grosso}

Nucleoplasma com grânulos de aspecto grosseiro. Nucléolo, célula em divisão e citoplasma não-fluorescentes (Figura 6).

\section{Pontilhado grosso reticulado}

Nucleoplasma com grânulos de aspecto grosseiro que se organizam em retículos associados a antígenos da matriz celular. Nucléolo, célula em divisão e citoplasma nãofluorescentes.

\section{Pontilhado fino}

Nucleoplasma com granulação fina. Nucléolo, célula em divisão e citoplasma não-fluorescentes (Figura 7).

No subgrupo dos pontilhados com mitose fluorescente temos os laudos a seguir.

\section{Pontilhado centromérico (laudo obrigatório)}

Nucleoplasma da célula apresenta-se em interfase, pontilhado com um número constante de 46 pontos. Nucléolo normalmente não-fluorescente, célula em divisão pontilhada e citoplasma não-fluorescente (Figura 8).

No subgrupo da mitose fluorescente temos como laudo opcional o que se segue.

\section{Pontilhado fino denso}

Nucleoplasma da célula em interfase apresenta-se como um pontilhado fino denso, de aspecto quase homogêneo, e nucléolo não-fluorescente. A célula em divisão também apresenta decoração em pontilhado fino denso, quase homogêneo, dos cromossomos, na placa metafásica, com citoplasma não-fluorescente (Figura 9).

\section{Padrões nucleolares}

O consenso recomenda que os padrões nucleolares sejam relatados como padrão nucleolar (laudo mínimo). Como informação adicional pode o observador relatar os laudos que se seguem. 


\section{Nucleolar homogêneo}

Nucléolo homogêneo, a célula em divisão e o citoplasma não-fluorescentes (Figura 10).

\section{Nucleolar aglomerado}

Coloração de forma indefinida nos cromossomos. O nucléolo se apresenta com grumos de intensa fluorescência. A célula em divisão mostra-se amorfa, com coloração indefinida dos cromossomos da placa metafásica. Citoplasma e núcleo não-fluorescentes (Figura 11).

\section{Nucleolar pontilhado}

O nucléolo apresenta-se com pontos isolados que tendem a confluir. A célula em divisão exibe pontos isolados (máximo de dez) e brilhantes na placa de cromossomos em metáfase. Citoplasma normalmente não-fluorescente (Figura 12).

\section{Padrões citoplasmáticos}

Os padrões citoplasmáticos são divididos em dois grandes grupos: fibrilar e pontilhado.

\section{Citoplasmático fibrilar}

O laudo que caracteriza o grupo é obrigatório; já as três subdivisões do grupo são opcionais.

\section{Citoplasmático fibrilar linear}

Fibras de estresse que constituem o citoesqueleto decoradas de forma retilínea, cruzando toda a extensão da célula e não respeitando os limites nucleares. Núcleos e nucléolos não-fluorescentes (Figura 13).

\section{Citoplasmático fibrilar filamentar}

Decoração de filamentos com acentuação uni ou bipolar em relação à membrana nuclear. Núcleos e nucléolos não-fluorescentes (Figura 14).

\section{Citoplasmático fibrilar segmentar}

Apenas segmentos curtos das fibras de estresse se encontram fluorescentes. Núcleo e nucléolos negativos. Nas células em divisão, podemos observar, eventualmente, grânulos intensamente fluorescentes que correspondem à forma globular das proteínas do citoplasma (Figura 15).

\section{Citoplasmático pontilhado}

O laudo que caracteriza o grupo e o subgrupo polar é obrigatório; já as quatro subdivisões restantes são opcionais.

\section{Citoplasmático pontilhado polar}

Este também é um laudo obrigatório, pois evidencia cisternas do aparelho de Golgi. A decoração é apenas citoplasmática em pontos agrupados de situação perinuclear, normalmente em apenas um pólo nuclear. Núcleo, nucléolo e célula em divisão não-fluorescentes (Figura 16).

\section{Citoplasmático pontilhado com pontos isolados}

Pontos definidos de número variável por toda a extensão do citoplasma. Núcleo, nucléolo e célula em divisão não-fluorescentes (Figura 17).

\section{Citoplasmático pontilhado fino denso}

Fluorescência de finos, densos e confluentes pontos, chegando à quase homogeneidade. O núcleo pode ou não apresentar uma leve decoração homogênea na área do nucléolo. A célula em divisão é não-fluorescente (Figura 18).

\section{Citoplasmático pontilhado fino}

Pontos definidos em grande número e densidade; célula em divisão e nucléolo não-fluorescentes (Figura 19).

\section{Citoplasmático pontilhado reticulado}

Fluorescência em retículo por todo o citoplasma. Núcleo, nucléolo e célula em divisão não-fluorescentes (Figura 20).

\section{Aparelho mitótico}

O grupo de antígenos do aparelho mitótico foi subdividido em três subgrupos de laudo obrigatório.

\section{Centríolo}

Ponto fluorescente isolado na célula em repouso (interfase) que se divide em dois e migra ao pólo oposto do núcleo à medida que a célula entra em divisão (Figura 21).

\section{Ponte intercelular}

Antígenos que formam a união entre célula-mãe e célula-filha ao final da telófase. Podem ser observados com fluorescência intensa na ponte citoplasmática, que sofrerá clivagem ao final da divisão celular (Figura 22).

\section{Fuso mitótico}

O fuso mitótico poderá ser observado de forma diferenciada em duas situações: 1) na presença de anticorpos 
contra a proteína NuMA 1 (antígeno associado à mitose do tipo 1), encontramos intensa fluorescência do tipo pontilhado fino denso no nucleoplasma das células em repouso e decoração em cone dos pólos do fuso mitótico nas células que estão em mitose. Citoplasma não-fluorescente; 2) na presença do antígeno NuMA 2, as células em repouso se encontram não-fluorescentes em todas as suas estruturas. Há decoração intensa e grosseira dos pólos mitóticos das células em divisão, e as pontes intercelulares são positivas em telófase. Citoplasma não-fluorescente (Figuras 23 e 24).

\section{Entidades patrocinadoras}

Bion Diagnostics; Bio-Rad; BioSystems - Reagents \& Instruments; CPEI (Central de Produtos Enzimáticos e Imunológicos); Conciteg/GO; Exame - Medicina Laboratorial/DF; GMK Diagnósticos/RS; Hemagen Diagnostics; Hospfar/GO; IMMCO Diagnostics; Instituto de Patologia Clínica H. Pardini/MG; Laboratório Amaral Costa/PA; Laboratório Atalaia/GO; Laboratório Fleury/SP; Laboratório de Imuno-Reumatologia e HLA - HC-UFG; Laboratório Padrão/GO; Laboratórios Cardiolab/RJ; Leica; Metanalysis - Centro de Diagnósticos Médicos/RS; Sociedada Brasileira de Análises Clínicas - Regional Goiás; Sociedade Brasileira de Patologia Clínica e Medicina Laboratorial; Sociedade Brasileira de Reumatologia; Sociedade Goiana de Patologia Clínica; The Binding Site; Universidade Católica de Goiás (UCG); Wama Diagnóstica.

Organização: Laboratório de Auto-Imunidade UCG (LAI-CBB-UCG) - Universidade Católica de Goiás - Corpo técnico: professora Irmtraut Araci Hoffmann Pfrimer, professor Paulo Luiz Carvalho Francescantonio, professora Fabiana Nunes de Carvalho Guimarães, professor Wilson de Melo Cruvinel, Péricles Lopes Dourado (BIC/VPG-UCG); Departamento de Biomedicina - CBB: professor Paulo Roberto de Melo Reis.

\section{Referências}

I. Andrade, L.E.C. et al. Two major autoantigen-antibody systems of the mitotic spindle apparatus. Arthritis \& Rheumatism, 39: 1643-53, 1996.

2. Barland, P. \& Lipstein, E. Selection and use of laboratory tests in the rheumatic diseases. Am. J. Med., 100: 16-23,1996.

3. Bonfa, E. et al. Association between lulus psychosis and antiribossomal P protein antibodies. N. Engl. .. Med., 31 7: 265, 1987.

4. Bradwell,A.R.; Stokes, R.P.\& Johnson G.D. Atlas of hep-2 patterns. England: KNP Group Ltd. 1995.

5. Doi, M.E. $\bigcirc$ uso de diferentes substratos na investigação dos anticorpos antinucleares em doenças reumáticas sistêmicas. Rev. Bras. Reumatol., 35: 16-20,1995.

6. Ferreira, W.A. \& Ávila, S.L.M. Diagnóstico laboratorial das principais doenças infecciosas e auto-imunes. 2 a ed. Rio de Janeiro: Editora Guanabara Koogan S.A., 2001.

7. Fritzler, M.J. \& Rattner J.B. Idetification of newer autoantibodies and their clinical relevance. Rev. Bras. Reumatol., 38: I4755, 1998

8. Hargraves, M.M.; Richmond, H. \& Morton, R. Presentation of 2 bone marrow elements: "tart" cell and "L.E." cell. Proceed Mayo Clin., 23: 25-8, 1948.

9. Keren, D.F. \& Warren, J.S. Diagnostic immunology. Baltimore: Williams \& Wilkins, 1992

10. Koh,W-H. et al. Characterisation of anticytoplasmic antibodies and their clinical associations. Annal of the Rheumatic Diseases, 54: 269-73, 1995.

I I. Krapf, A. et al. Atlas of immunofluorescent antibodies. Munich: Urban \& Schwarzenberg, 1996.

12. Lahita, R.G.; Chiorazzi, N. \& Reeves, W.H. Textbook of the autoimmune diseases. Philadelphia: Lippincott Williams \& Wilkins, 2000.
13. Moore, A.E. et al. Culture characteristics of four permanent lines of human cancer cells. Cancer Res., I 5: 598-602, 1955.

14. Morrow, J. et al. Autoimmune reumatic disease. $2^{\text {a }}$ ed. Hong Kong: Oxford University Press, 1999.

15. Parslow, T. et al. Medical immunology. USA: McGraw-Hill Companies, 2001 .

16. Peter, J.B. \& Shoenfeld,Y. Autoantibodies. Netherlands: Elservier 1996.

17. Rose, N.R. \& Mackay, I.R. The autoimmune diseases. 3a ed. USA: Academic Press, 1998.

18. Toolan, H.W. Transplantable human neoplasms maintained in cortisone-treated laboratory animals: H.S.\#1; H.Ep.\#2; H.Ep.\#3; and H.Emb.Rh\#I. Cancer Res., 14: 660-6, 1954.

19. Utiyama, S.R.R. et al. Use of different substrates for ANA detection in systemic rheumatic diseases. Rev. Bras. Reumatol., 35: I |-5, 1995.

20. Von Mühlen, C.A. \& Tan, E.M. Autoantibodies in the diagnosis of systemic rheumatic diseases. Sem. Arthritis Rheum., 24: 323-7, 1995
Endereço para correspondência

Paulo Luiz C. Francescantonio

Laboratório de Auto-Imunidade (LAI) e-mail: CBB@UCG.br 


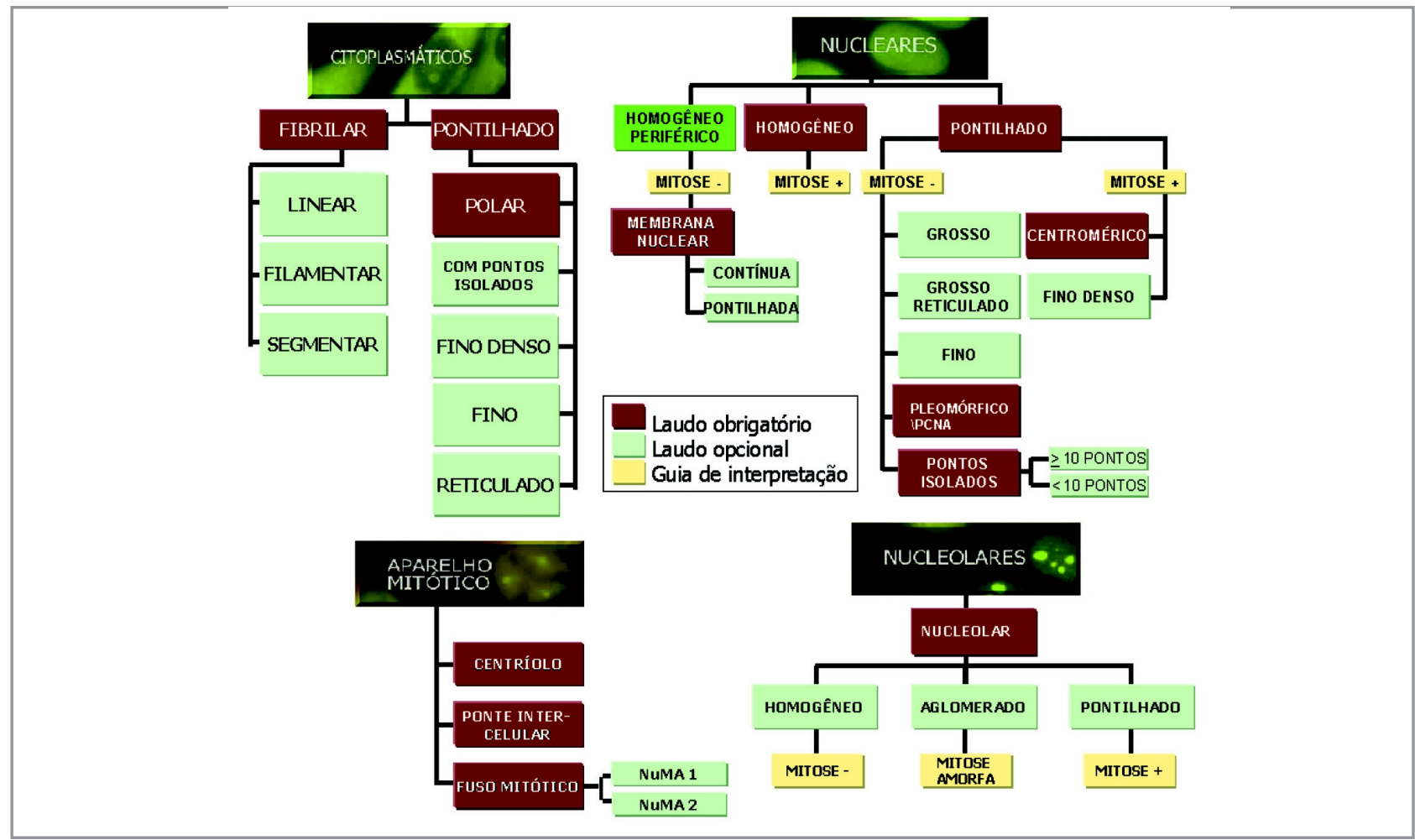

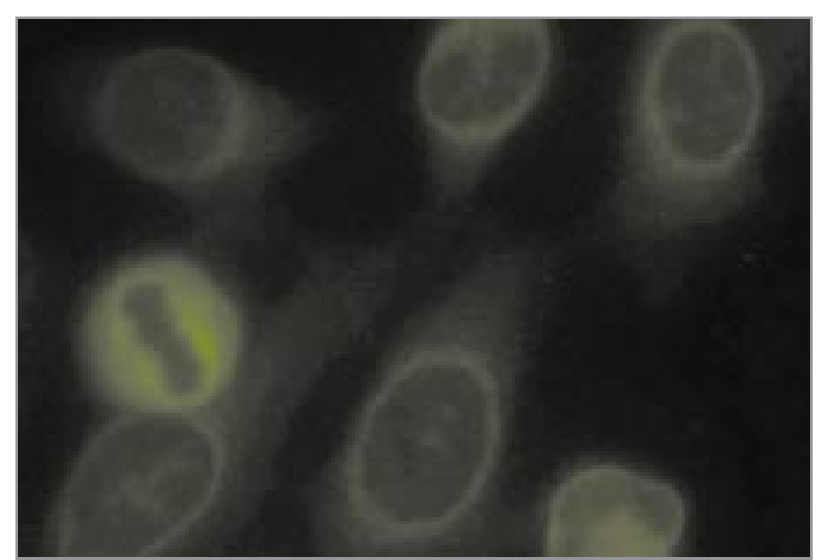

Figura 2 - Nuclear tipo membrana nuclear

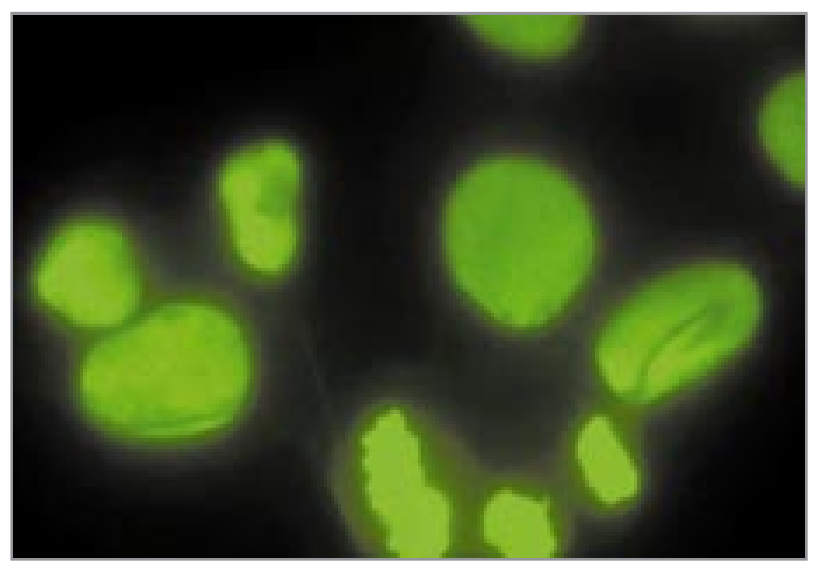

Figura 3 - Nuclear homogêneo

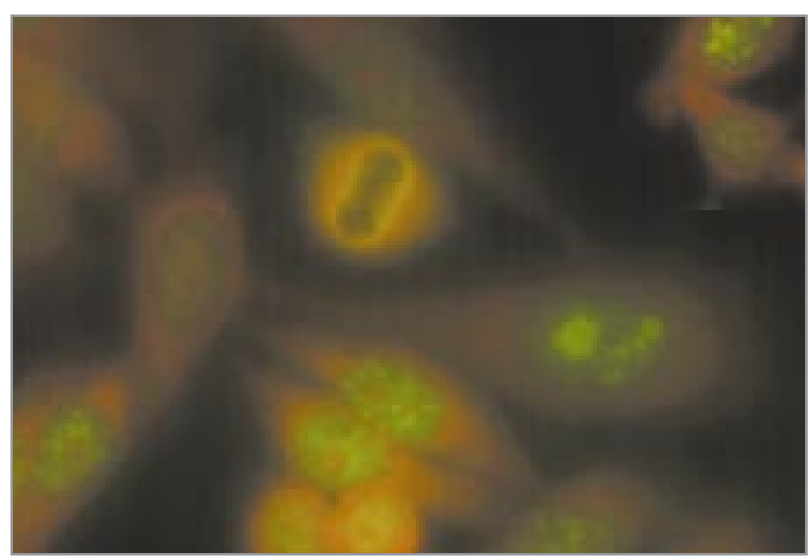

Figura 4 - Nuclear pontilhado pleomórfico

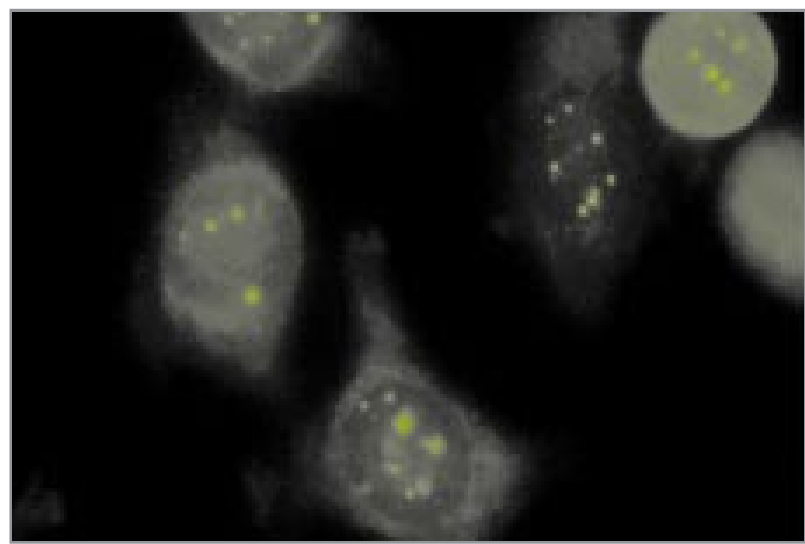

Figura 5 - Nuclear pontilhado do tipo pontos isolados 


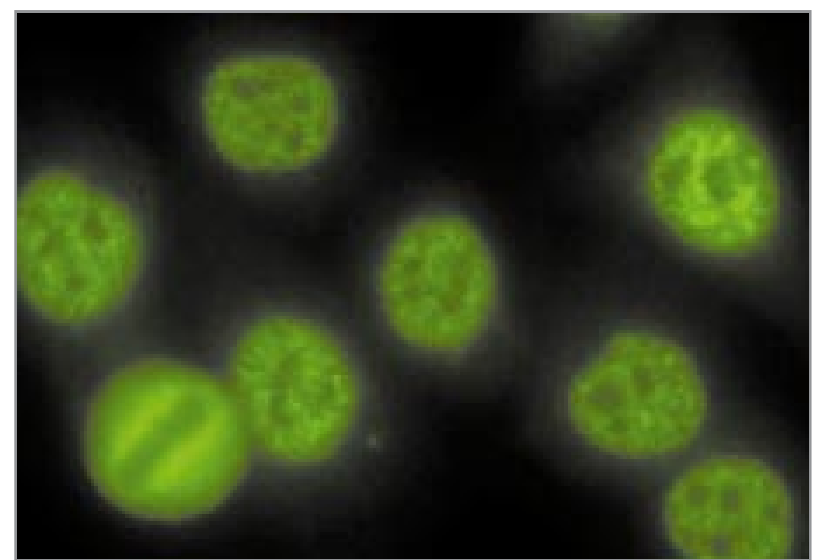

Figura 6 - Nuclear pontilhado grosso

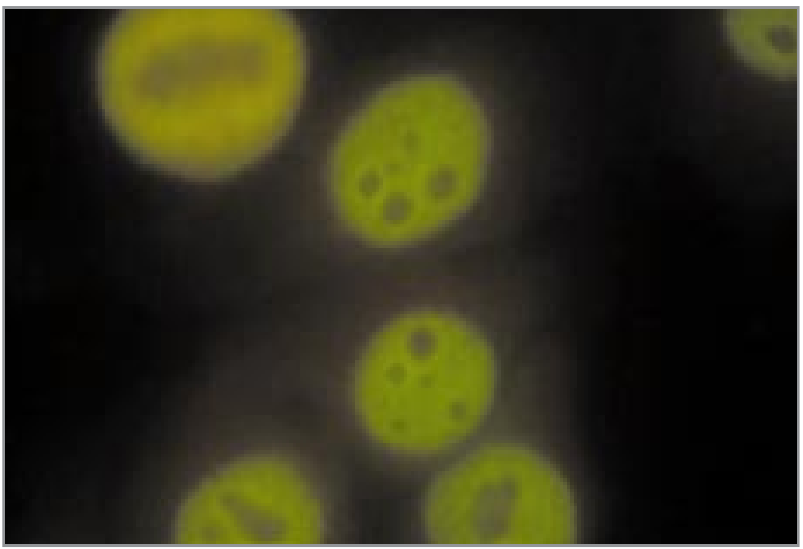

Figura 7 - Nuclear pontilhado fino

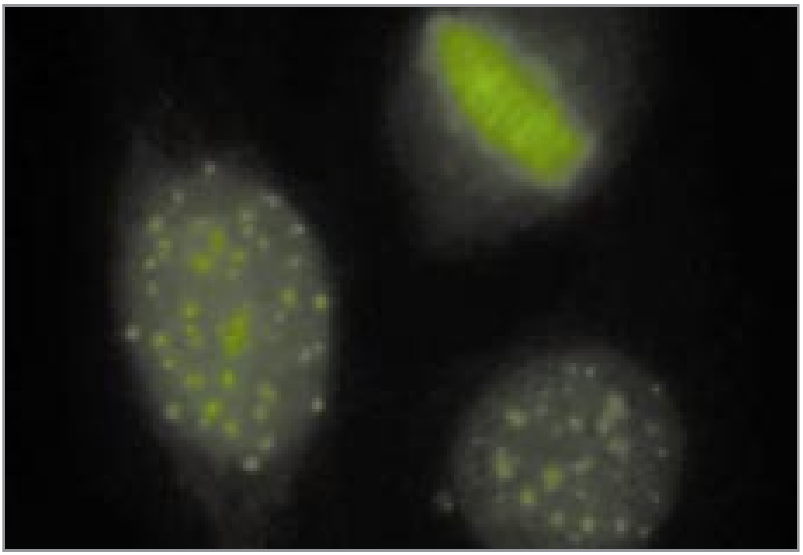

Figura 8 - Nuclear pontilhado centromérico

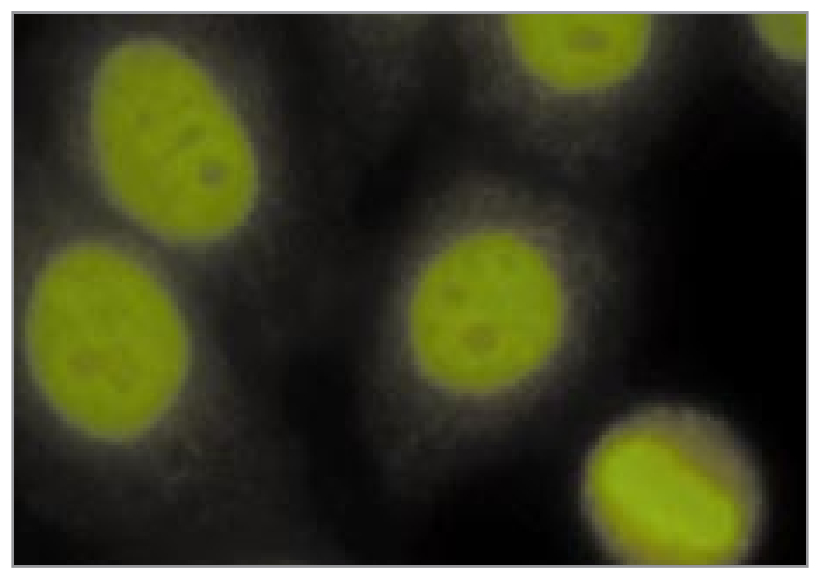

Figura 9 - Nuclear pontilhado fino denso

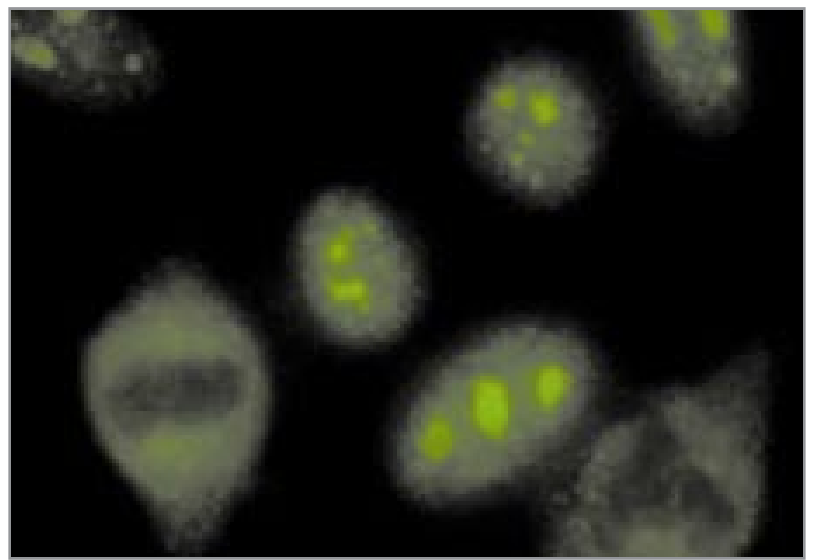

Figura 10 - Nucleolar homogêneo

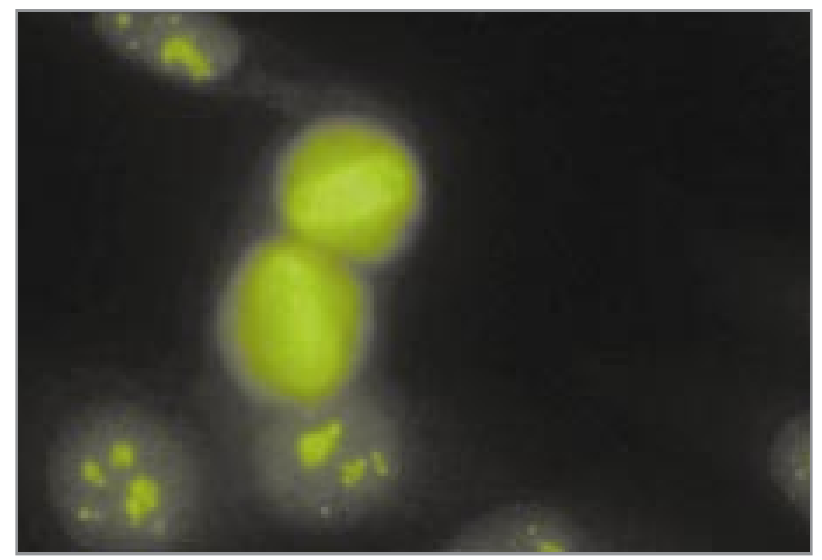

Figura 11 - Nucleolar aglomerado 


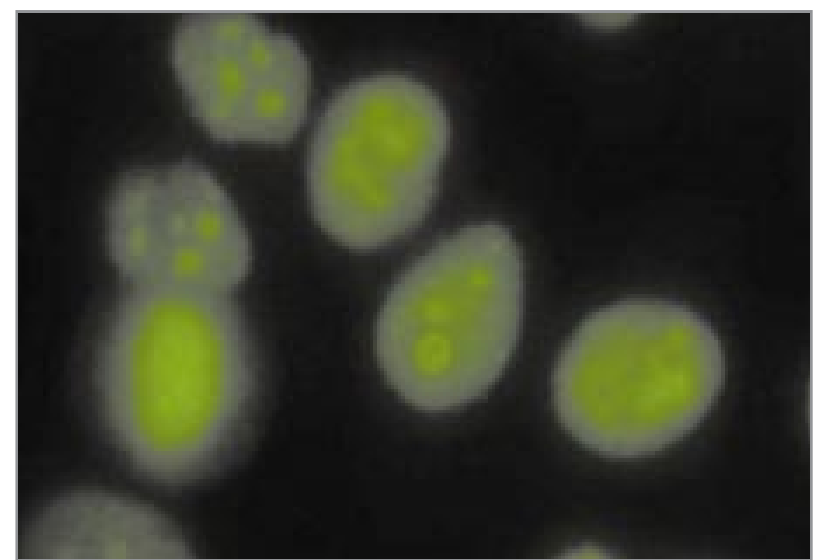

Figura 12 - Nucleolar pontilhado

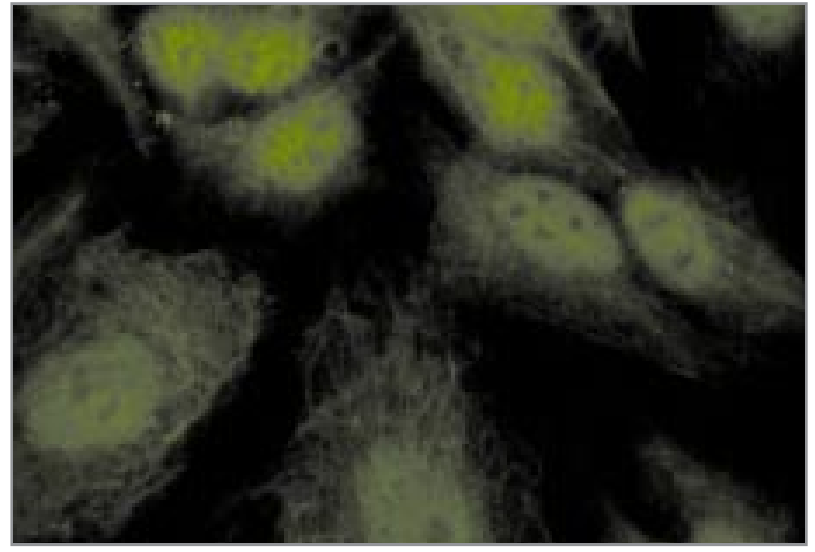

Figura 13 - Citoplasmático fibrilar linear

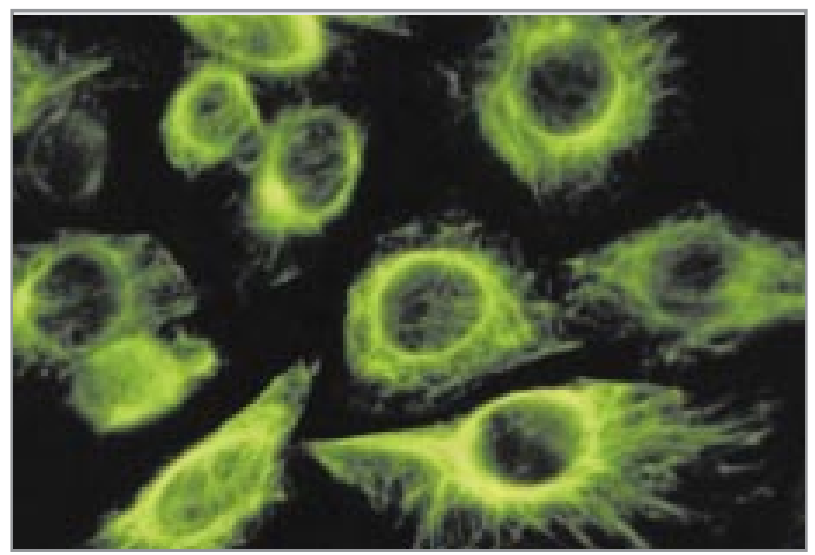

Figura 14 - Citoplasmático fibrilar filamentar

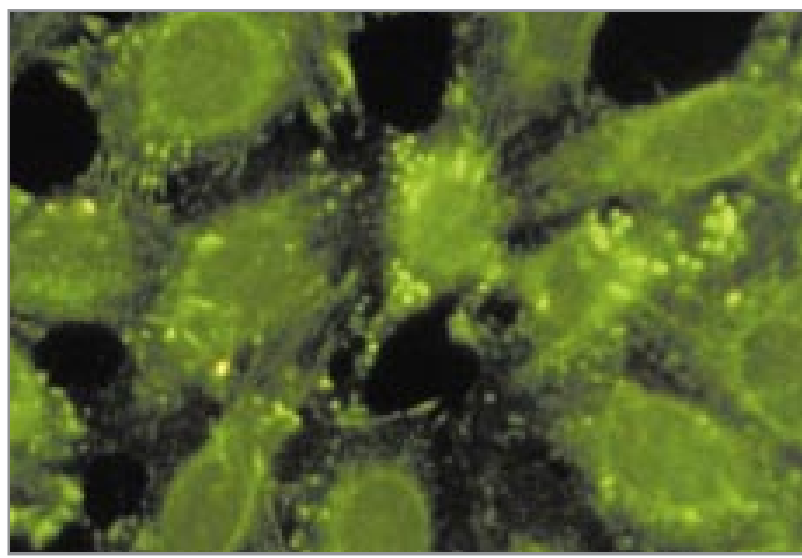

Figura 15 - Citoplasmático fibrilar segmentar

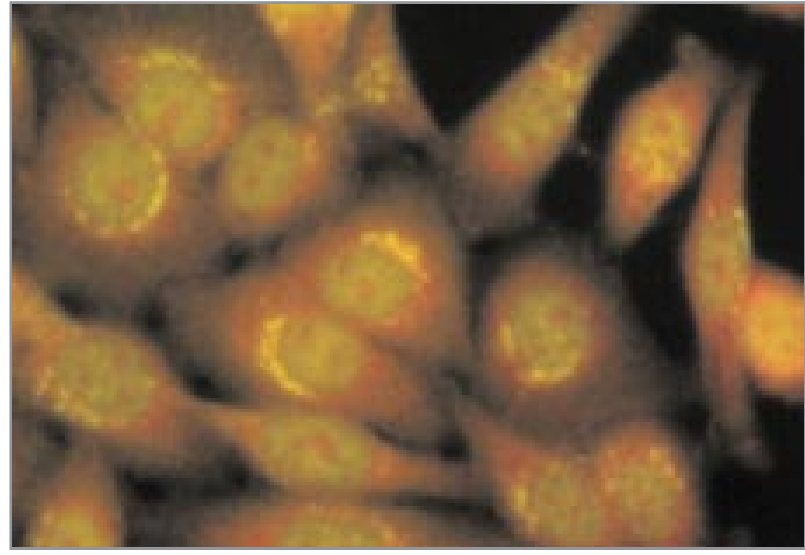

Figura 16 - Citoplasmático pontilhado polar

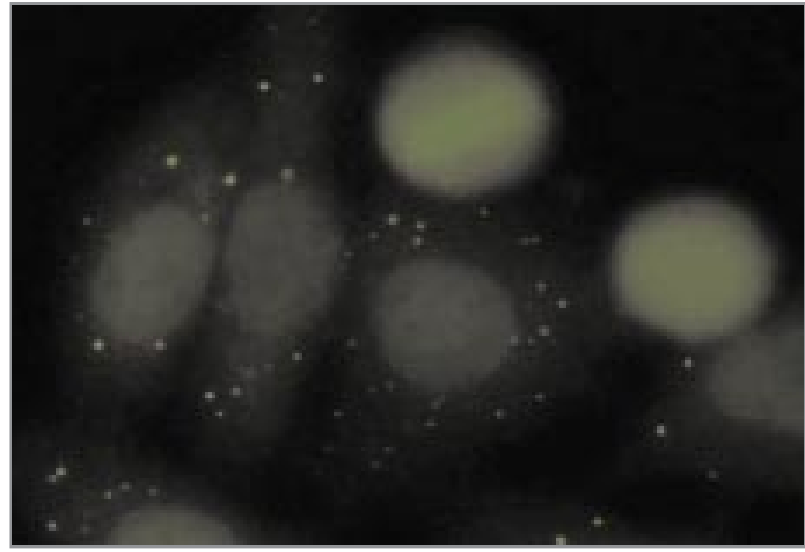

Figura 17 - Citoplasmático pontilhado com pontos isolados 


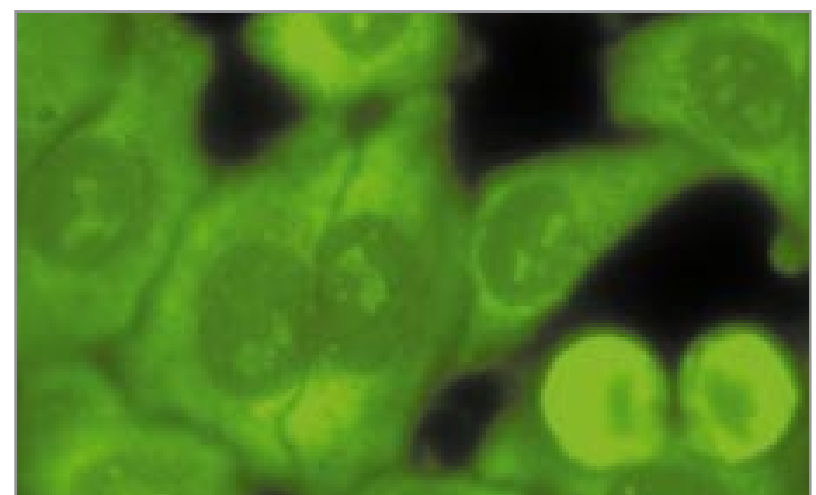

Figura 18 - Citoplasmático pontilhado fino denso

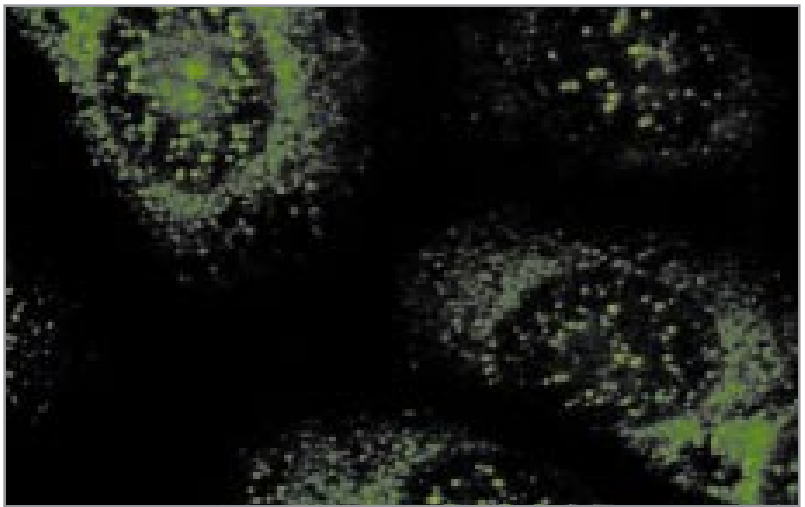

Figura 19 - Citoplasmático pontilhado fino

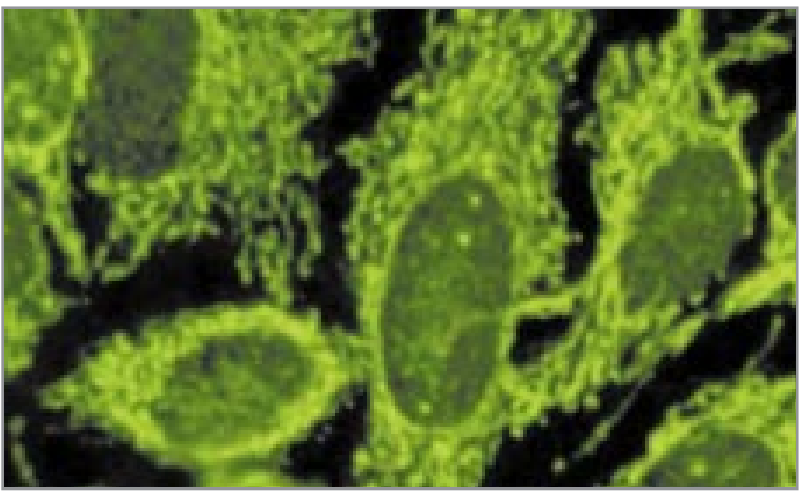

Figura 20 - Citoplasmático pontilhado reticulado

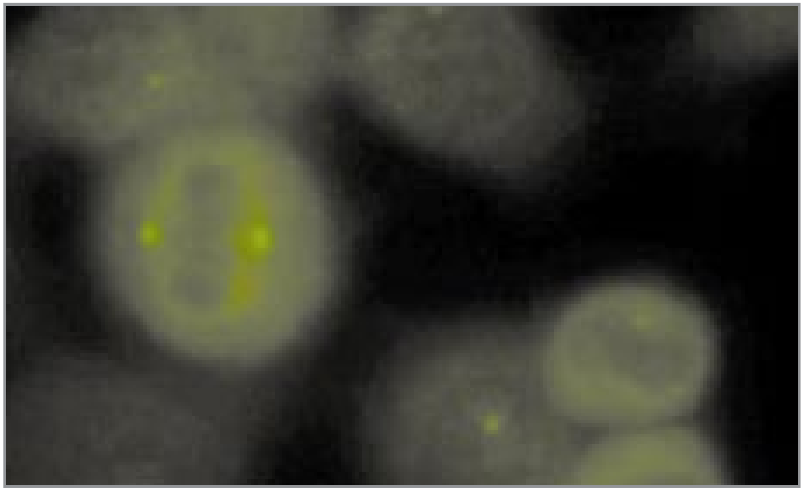

Figura 21 - Aparelho mitótico: centríolo

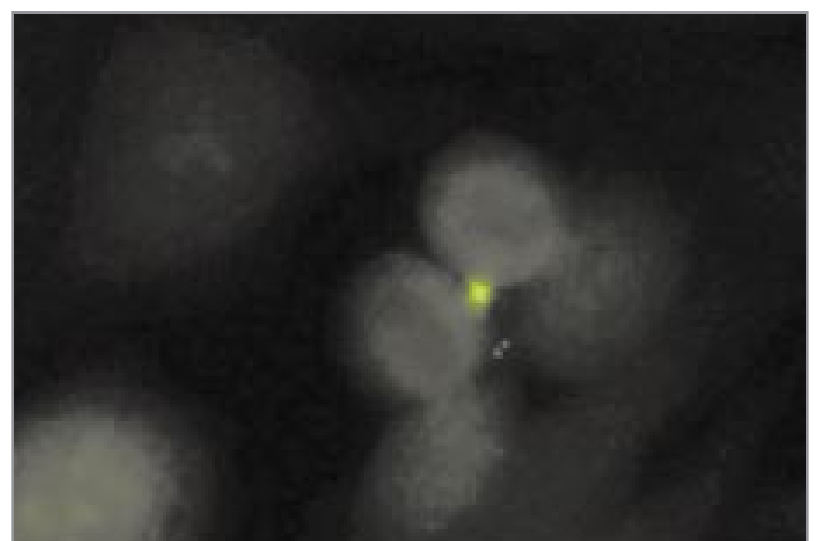

Figura 22 - Aparelho mitótico: ponte intercelular

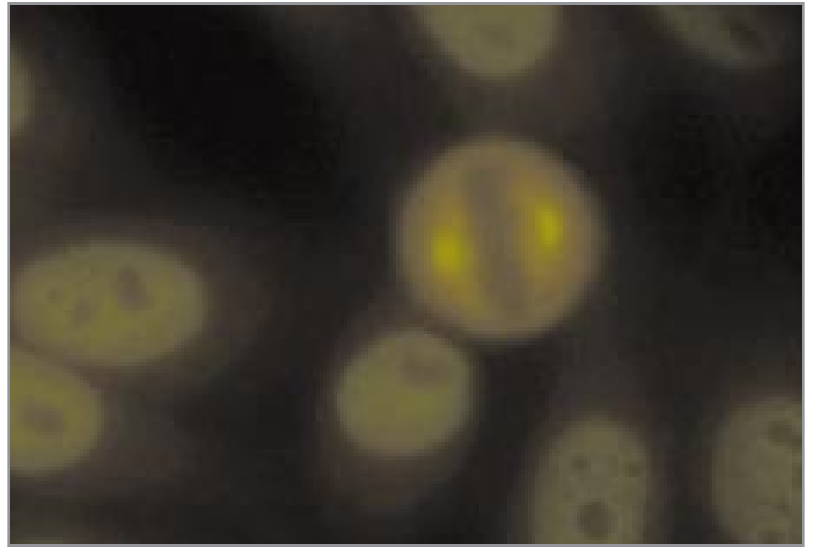

Figura 23 - Fuso mitótico NuMA 1

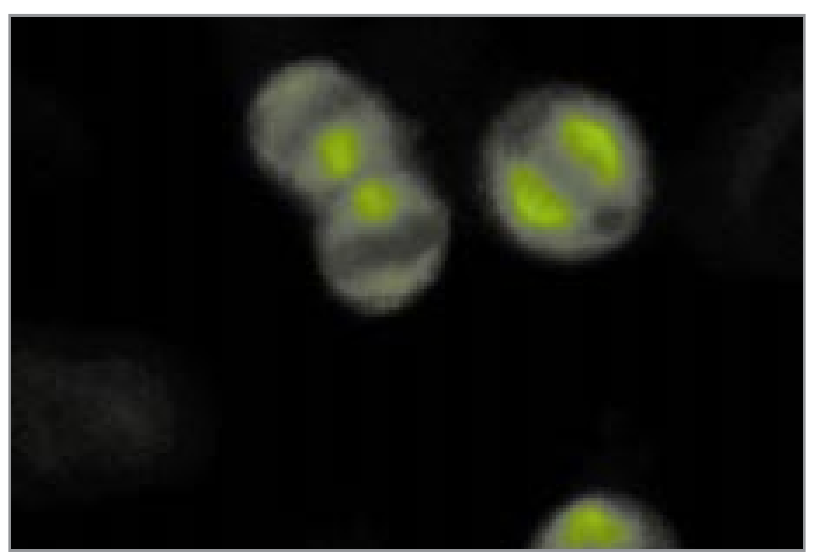

Figura 24 - Fuso mitótico NuMA 2 